\title{
ASSOCIATION BETWEEN HYPERTENSION AND THE SEVERITY OF NEW ONSET ISCHEMIC STROKE IN DIABETIC PATIENTS
}

\author{
H SINA $^{1}$, T MUSTARY ${ }^{2}$, KGU AHMED ${ }^{3}$, AH CHOWDHURY ${ }^{4}$, K SAHA ${ }^{5}$, M ARIFUZZAMAN ${ }^{6}$, \\ AR SIDDIQUE ${ }^{7}$, I ALAM ${ }^{8}$, SA DHALI ${ }^{9}$, SU AHMED ${ }^{10}$
}

\begin{abstract}
Objective: To evaluate the association between hypertension and the severity of new onset ischemic stroke patient with diabetes mellitus.

Method: This Cross sectional study was carried out in the Department of Neurology, BSMMU, Dhaka, from February 2013 to September 2014 on 50 patients with first attack of ischemic stroke with DM. mRS was measured on $14^{\text {th }}$ day of the stroke. During this period other important relevant investigations were also recorded.

Result: In this study, out of 50 patients, $40.0 \%$ were in age group 51-60 years and the mean age of the patients was $58.9 \pm 9.6$ years with a range from 30 to 75 years. Males were $52.0 \%$ and females were 48.0\%. Male to female ratio was 1.08:1. It was observed that more than one third (36.0\%) patients were current smoker, 9(18.0\%) were former smoker and 23(46.0\%) were non smoker. More than half of the patients had hypertension (58.0\%). Mean systolic BP was 129 $\pm 16 \mathrm{mmHg}$ with a range from 90 to $160 \mathrm{mmHg}$ and the mean diastolic BP was $81 \pm 11 \mathrm{mmHg}$ with a range from 60 to $100 \mathrm{mmHg}$. No association was found between hypertension with severity of new onset ischemic stroke in Diabetic patients.
\end{abstract}

Conclusion: As per study result it can be concluded that there is no association between hypertension and the severity of new onset ischemic stroke in Diabetic patients.

Keywords: Hypertension, Ischemic stroke, diabetes mellitus

J Dhaka Med Coll. 2019; 28(1) : 7-10

\section{Introduction:}

Stroke is defined as a sudden onset of a neurological deficit caused by an acute focal injury to the central nervous system due to a vascular cause. ${ }^{1}$ The incidence of strokes occurring every year worldwide is about 17 million and it is the second leading cause of death after coronary artery disease. ${ }^{2}$ Ischemic strokes are the most common (H"85\%), the rest are hemorrhagic which include cerebral and subarachnoid (H"15\%). ${ }^{3}$

Stroke is the third leading cause of death in Bangladesh (Islam et al. 2013). ${ }^{4}$ The World
Health Organization ranks Bangladesh's mortality rate due to stroke as number 84 in the world. The reported prevalence of stroke in Bangladesh is $0.3 \%$. The high number of disability-adjusted life-years lost due to stroke (485 per 10,000 people) show that stroke severely impacts Bangladesh's economy (Islam et al. 2013). ${ }^{4}$

Hypertension (HTN) is the most common modifiable risk factor for stroke, with blood pressure (BP) reduction being associated with a reduced rate of stroke recurrence ${ }^{5}$ However, how best to treat HTN during the acute period

1. Dr. Hashmi Sina, Assistant Professor, Neurology, Dhaka Medical College

2. Dr. Tamanna Mustary Thesis Part Student, Dermatology and Venereal Diseases, Dhaka Medical College.

3. Dr. Kazi Gias Uddin Ahmed, Associate Professor, Neurology, Dhaka Medical College.

4. Dr. Ahmed Hossain Chowdhury, Associate Professor, Neurology, Dhaka Medical College.

5. Dr. Kanol Saha, Associate Professor, Neurology, Dhaka Medical College.

6. Dr. Mohammad Arifuzzaman, Assistant Professor, Neurology, Dhaka Medical College.

7. Abu Raihan Siddique, Assistant Professor, Gastroenterology

8. Dr. lftikherAlam, Junior Consultant, Neurology. Dhaka Medical College.

9. Dr. SabbirAhmed Dhali, Registrar, Neurology, Dhaka Medical College.

10. Dr. Sharif Uddin Ahmed, Assistant Professor, DGHS

Correspondence : Dr. Hashmi Sina, Assistant Professor, Neurology, Dhaka Medical College

Received: 10 February 2019

Revision: 02 March 2019

Accepted: 30 Mach 2019 
of ischemic stroke is less well established. In a recent study using data collected from nationwide Emergency Departments, 69\% of presenting patients had a systolic blood pressure of $>139 \mathrm{~mm} \mathrm{Hg}$, while other studies have found blood pressures of $>150 / 90 \mathrm{~mm} \mathrm{Hg}$ in up to $84 \%$ of patients. ${ }^{6,7}$ Although the management of BP in acute ischemic stroke has been addressed in many clinical trials, there are no definitive data showing that treatment in the hyperacute or acute setting alters clinical outcomes. ${ }^{8,9}$

The existing studies have shown that the main cause of ischemic stroke is the lesion of vascular wall. Diabetes mellitus is one of the major risk factors of atherosclerosis, which can accelerate the process of vascular lesion. ${ }^{10}$

\section{Method:}

This Cross sectional study was carried out in the Department of Neurology, BSMMU, Dhaka, from February 2013 to September 2014. This study was conducted on 50 patients with first attack of ischemic stroke with DM. On $14^{\text {th }}$ day of stroke, patient's mRS was done along with HbA1c. During this period other important relevant investigations were recorded. Statistical software SPSS 12.0 was used for analysis. A p value of $<0.05$ was taken as level of significance.

\section{Results:}

In this study, it was observed that majority of the patients $(40.0 \%)$ were in age group 51-60 years and the mean age was $58.9 \pm 9.6$ years with a range from 30 to 75 years. $26(52.0 \%)$ patients were male and $24(48.0 \%)$ were female. Male to female ratio was 1.08:1. It was observed that more than one third $(36.0 \%)$ of the patients were current smoker, $9(18.0 \%)$ were former smoker and 23(46.0\%) were non smoker. It was observed that majority of the 29(58.0\%) patients had hypertension. Mean systolic blood pressure was $129 \pm 16 \mathrm{mmHg}$ with a range from 90 to $160 \mathrm{mmHg}$ and mean diastolic blood pressure was $81 \pm 11 \mathrm{mmHg}$ with a range from 60 to 100 $\mathrm{mmHg}$ in this study.

Mean modified ranking scale on 14th day of stroke were $2.7 \pm 0.8$ and $2.6 \pm 1.0$ in hypertensive and normotensive patients respectively. The mean difference was not statistically significant ( $p>0.05)$ between two groups.

\section{Table I}

Demographic and clinical profile of the study subjects $(n=50)$

\begin{tabular}{lcc}
\hline & Frequency & Percentage \\
\hline Age (years) & & \\
$\leq 40$ & 4 & 8.0 \\
$41-50$ & 5 & 10.0 \\
$51-60$ & 19 & 40.0 \\
$61-70$ & 2 & 4.0 \\
$>70$ & $58.9 \pm 9.6$ & \\
Mean \pm SD & $(30-75)$ & \\
Range (min-max) & & \\
Gender & 26 & 52.0 \\
Male & 24 & 48.0 \\
Female & & \\
Smoking habit & 27 & 54.0 \\
Current & 23 & 46.0 \\
Non smoker & 29 & 58.0 \\
Hypertension & $129 \pm 16$ & \\
Systolic BP (mmHg) & & \\
[Mean \pm SD] & & \\
Diastolic BP (mmHg) & $81 \pm 11$ & \\
[Mean \pm SD] & & \\
\hline
\end{tabular}

Table II

Association between hypertension with modified ranking scale on $14^{\text {th }}$ day of stroke $(n=50)$

\begin{tabular}{lcccc}
\hline Hypertension & $\mathrm{n}$ & $\begin{array}{c}\text { Modified ranking scale (On14th day of stroke) } \\
\text { Mean } \pm \text { SD }\end{array}$ & P-value \\
\hline Yes & 29 & $2.7 \pm 0.8$ & $1-3$ & 0.134 \\
No & 21 & $2.6 \pm 1.0$ & $1-5$ & \\
\hline
\end{tabular}

$\mathrm{P}$ value reached from unpaired t-test 
Table-III

Dependent Variable: Modified ranking Scale for Stroke Severity (mRS)

\begin{tabular}{lccccccccc}
\hline $\begin{array}{l}\text { Independent } \\
\text { variables }\end{array}$ & $\begin{array}{c}\text { Unstandardized } \\
\text { B (beta) }\end{array}$ & Wald & S.E. & Sig. & OR & \multicolumn{3}{c}{$\begin{array}{c}\text { Standardized } \\
\text { 95\% CI for OR }\end{array}$} \\
\hline Age & .106 & 5.421 & .046 & $.020^{*}$ & 1.112 & 0.2415 & 1.017 & 1.216 \\
Sex & -2.656 & 3.650 & 1.390 & .056 & .070 & -0.3063 & .005 & 1.071 \\
Smoking & -1.370 & 2.479 & .870 & .115 & .254 & -0.2400 & .046 & 1.399 \\
Hypertension & -.987 & 1.702 & .756 & .192 & .373 & -0.1154 & .085 & 1.641 \\
HBA1c & .847 & 6.025 & .345 & $.014^{*}$ & 2.332 & 0.2873 & 1.186 & 4.584 \\
Constant & -8.290 & 4.632 & 3.852 & .031 & .000 & 0.2415 & - & - \\
\hline
\end{tabular}

*Significant at 5 Percent level of significance

\section{Discussion:}

In this series it was observed that majority $(78.0 \%)$ patients were in $6^{\text {th }}$ and $7^{\text {th }}$ decade and the mean age was $58.96 \pm 9.58$ years with range from 30 to 75 years. Shuangxi et al. ${ }^{11}$ and Basu et al. ${ }^{12}$ showed the mean age was $60.5 \pm 8.65$ years varied from 45 to 81 years and the average age was $60.0 \pm 13$ years varied from 25 to 88 years respectively. Similarly, Doi et al. ${ }^{13}$ obtained the mean age $58.0 \pm 10.0$ years, which is consistent with the current study. On the other hand, Rathore et al. ${ }^{14}$ has observed higher mean age, which was $64.78 \pm 9.404$ years varied from $45-85$ years and the maximum frequency was seen between ages $55-74$ years. Similarly, Kamouchi et al. ${ }^{15}$ and Sare et al. ${ }^{16}$ showed the mean age of the study subjects was $69 \pm 12$ years and $68.9 \pm 12.1$ years respectively. The higher mean age may be due to increased life expectancy, geographical variations, racial and ethnic differences may have significant impacts.

In this study it was observed that $52.0 \%$ patients were male and $48.0 \%$ female and male to female ratio was $1.08: 1$, which is closely resembled with Shuangxi et al. ${ }^{11}$, Kamouchi et al. ${ }^{15}$, Rathore et al. ${ }^{14}$, Sare et al. ${ }^{16}$ and Basu et al. ${ }^{12}$ series, where all the above investigators found male predominance in their study.

In this present studies it was observed that more than one third $(36.0 \%)$ of the patients were current smoker, $18.0 \%$ were former smoker and $46.0 \%$ were non smoker. Shuangxi et al. ${ }^{11}$, Kamouchi et al. ${ }^{15}$ and Rathore et al. ${ }^{14}$ showed $38.9 \%, 46.0 \%$ and $57.0 \%$ study subjects were current smoker respectively. In another study, Doi et al. ${ }^{13}$ observed $50.1 \%$ patients were current smoker in their study, which were comparable with the current study.

In this current study it was observed that 58.0\% patients had hypertension. Similarly, Shuangxi et al. ${ }^{11}$ and Doi et al. ${ }^{13}$ found $55.6 \%$ and $43.3 \%$ of their study patients were hypertensive, respectively. Kamouchi et al. ${ }^{15}$ found $70.9 \%$ of patients hypertensive, Sare et al. ${ }^{10}$ found history of hypertension in $73.2 \%$ and Basu et al. ${ }^{12}$ obtained that the majority of the patients were hypertensive (74.0\%). Above results were higher than the current study.

In this present study, it was observed that the mean systolic BP was $129.25 \pm 15.98 \mathrm{mmHg}$ which varied from 90 to $160 \mathrm{mmHg}$. The mean diastolic BP was $81 \pm 10.77 \mathrm{mmHg}$ which varied from 60 to $100 \mathrm{mmHg}$. Doi et al. ${ }^{7}$ showed that the mean systolic blood pressure was $134.0 \pm 20.0 \mathrm{mmHg}$ and mean diastolic blood pressure was $81.0 \pm 11 \mathrm{mmHg}$, which was consistent with the current study. Kamouchi et al. ${ }^{15}$ showed the mean systolic blood pressure was $161.0 \pm 30.0 \mathrm{mmHg}$ and mean diastolic blood pressure was $88.0 \pm 18.0 \mathrm{mmHg}$, which were higher than the current study. Similarly higher systolic and diastolic blood pressure was also revealed by Rathore et al. ${ }^{14}$ and Sare et al. ${ }^{16}$.

\section{Conclusion}

Patients having new onset ischemic stroke with Diabetic Mellitus were predominant in $6^{\text {th }}$ decade and above and more common in male subjects. Finally it can be concluded that 
hypertension is not associated with stroke severity measured in $\mathrm{mRS}$ scale.

\section{References:}

01. Sacco RL, Kasner SE, Broderick JP, et al. An updated definition of stroke for the 21 st century: A statement for healthcare professionals from the American heart association/American stroke association. Stroke. 2013;44(7):2064-2089.

02. Lopez AD, Mathers CD, Ezzati M, Jamison DT, Murray CJ. Global and regional burden of disease and risk factors, 2001: systematic analysis of population health data. Lancet. 2006;367(9524):1747-1757.

03. Centers for Disease Control and Prevention, National Center for Health Statistics Underlying Cause of Death 1999-2013 on CDC WONDER Online Database, released 2015. Data are from the Multiple Cause of Death Files, 1999-2013, as compiled from data provided 2015. No Title.

04. Islam MN, Moniruzzaman M, Khalil MI, Basri R, Alam $\mathrm{MK}$, Loo KW, Gan SH. Burden of stroke in Bangladesh. International journal of stroke. 2013 Apr; 8(3):211-3.

05. Arima H, Chalmers J, Woodward M, Anderson C, Rodgers A, Davis S, et al. Lower target blood pressures are safe and effective for the prevention of recurrent stroke: the PROGRESS trial. J Hypertens. 2006;24:1201-1208.

06. Qureshi AI, Ezzeddine MA, Nasar A, Suri MF, Kirmani JF, Hussein HM, et al. Prevalence of elevated blood pressure in 563,704 adult patients with stroke presenting to the ED in the United States. Am J Emerg Med. 2007;25:32-38.

07. Wallace JD, Levy LL. Blood pressure after stroke. JAMA. 1981;246:2177-2180.

08. Olsen TS, Bruhn P, Oberg RG. Cortical hypoperfusion as a possible cause of 'subcortical aphasia'. Brain. 1986;109(Pt 3):393-410.
09. Lee JM, Zhai G, Liu Q, Gonzales ER, Yin K, Yan P, et al. Vascular permeability precedes spontaneous intracerebral hemorrhage in stroke-prone spontaneously hypertensive rats. Stroke. 2007; 38:3289-3291.

10. Pearson ER and McCrimmon RJ. 'Diabetes mellitus' In: Walker B, Colledge N, Ralton S, Penman I 22nd ed. 2014. Davidson's Principles and Practice of Medicine, Elsevier, London.

11. Shuangxi G, Song T, Bo S, Avinash C, Anna M, Hui F, Si C, Yuming X. Study of the relationship of glycated hemoglobin levels and neurological impairment and three months prognosis in patients with acute ischemic stroke. Life Sci J. 2012;9(2): 119-21.

12. Basu S, Sanyal D, Roy K, Bhattacharya KB. Is poststroke hyperglycemia a marker of stroke severity and prognosis: A pilot study. Neurology Asia. 2007 Jun;12:13-9.

13. Doi Y, Ninomiya T, Hata J, Fukuhara M, Yonemoto $\mathrm{K}$, Iwase M, Iida M, Kiyohara Y. Impact of Glucose Tolerance Status on Development of Ischemic Stroke and Coronary Heart Disease in a General Japanese Population. Stroke. 2010 Feb 1;41(2):203-9.

14. Rathore JA, Kango ZA, Mehraj A. Predictors of mortality after acute stroke a prospective hospital based study. J Ayub Med Coll Abbottabad. 2011 Jun 1;23(2):144-6.

15. Kamouchi M, Matsuki T, Hata J, Kuwashiro T, Ago T, Sambongi Y, Fukushima Y, Sugimori H, Kitazono T, FSR Investigators. Prestroke glycemic control is associated with the functional outcome in acute ischemic stroke. Stroke. 2011 Oct 1;42(10):2788-94.

16. Sare GM, Ali M, Shuaib A, Bath PM. Relationship between hyperacute blood pressure and outcome after ischemic stroke. Stroke. 2009 Jun 1;40(6): 2098-103. 